Provided for non-commercial research and education use. Not for reproduction, distribution or commercial use.

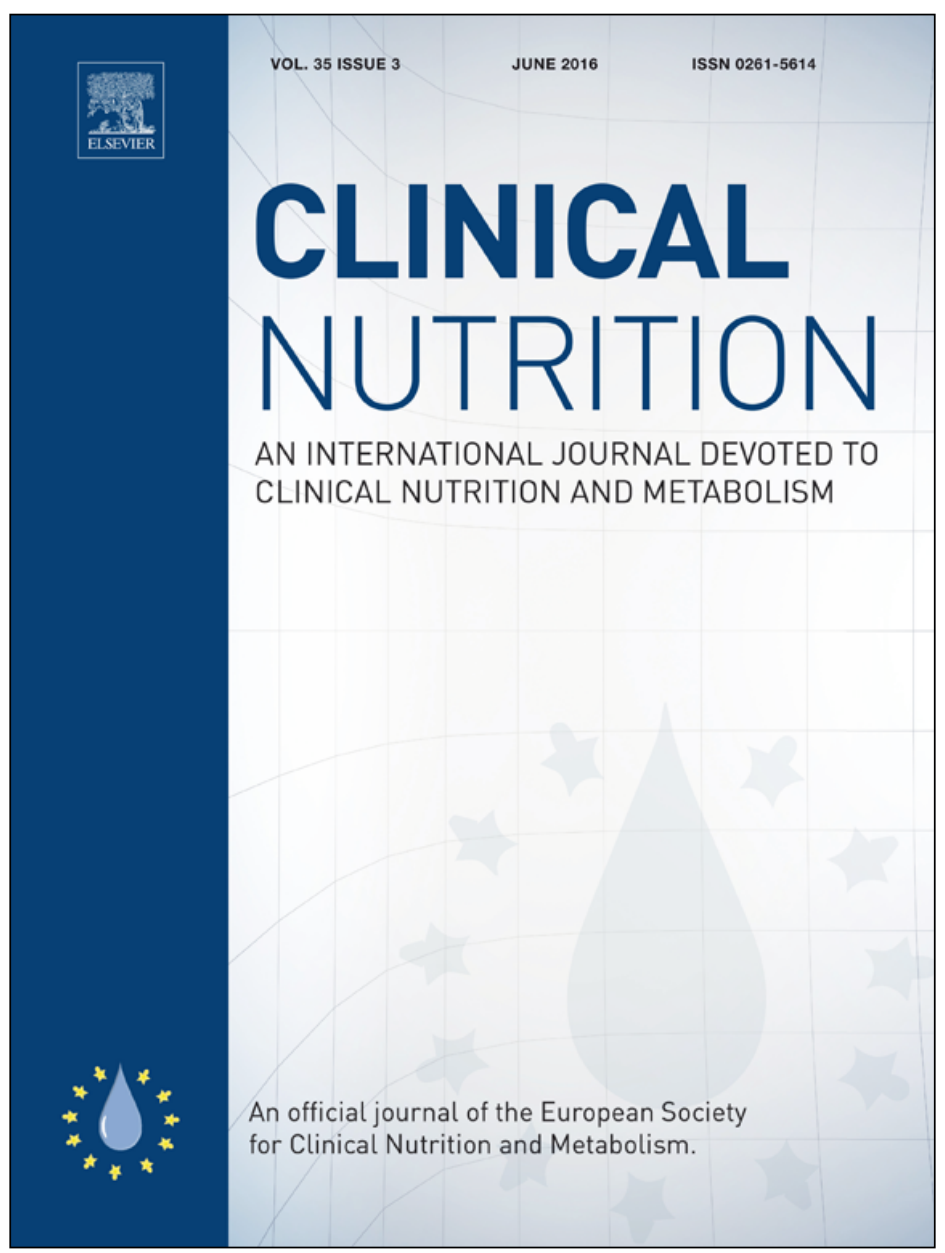

This article appeared in a journal published by Elsevier. The attached copy is furnished to the author for internal non-commercial research and education use, including for instruction at the author's institution and sharing with colleagues.

Other uses, including reproduction and distribution, or selling or licensing copies, or posting to personal, institutional or third party websites are prohibited.

In most cases authors are permitted to post their version of the article (e.g. in Word or Tex form) to their personal website or institutional repository. Authors requiring further information regarding Elsevier's archiving and manuscript policies are encouraged to visit:

http://www.elsevier.com/authorsrights 
Randomized control trials

\title{
Efficacy of docosahexaenoic acid-enriched formula to enhance maternal and fetal blood docosahexaenoic acid levels: Randomized double-blinded placebo-controlled trial of pregnant women with gestational diabetes mellitus
}

\author{
Yoeju Min a, *, Ovrang Djahanbakhch ${ }^{\text {b, c }}$, Joanne Hutchinson ${ }^{\text {b, a }}$, Sofia Eram ${ }^{\text {a }}$, \\ Amritpal S. Bhullar ${ }^{a}$, Irene Namugere ${ }^{b}$, Kebreab Ghebremeskel ${ }^{\text {a }}$ \\ a Lipidomics and Nutrition Research Centre, Faculty of Life Sciences and Computing, London Metropolitan University, London, UK \\ ${ }^{\mathrm{b}}$ Newham University Hospital National Health Service Trust, London, UK \\ ${ }^{\mathrm{c}}$ Academic Department of Women's Health, Queen Mary's School of Medicine, University of London, London, UK
}

\section{A R T I C L E I N F O}

\section{Article history:}

Received 13 October 2014

Accepted 31 May 2015

\section{Keywords:}

Gestational diabetes mellitus

Pregnancy

Docosahexaenoic acid

\begin{abstract}
S U M M A R Y
Background \& aims: Gestational diabetes mellitus (GDM) compromises the level of docosahexaenoic acid (DHA) in phospholipids of maternal and fetal red blood cells and fetal plasma. This is of some concern because of the importance of DHA for fetal neuro-visual development. We have investigated whether this abnormality could be rectified by supplementation with DHA-enriched formula.

Methods: Women with GDM $(\mathrm{n}=138)$ recruited from Newham University Hospital, London received two capsules of DHA-enriched formula (active-group) or high oleic acid sunflower seed oil (placebo-group) from diagnosis until delivery. Maternal (baseline and delivery) and fetal (cord blood) red blood cell and plasma phospholipid fatty acid composition, and neonatal anthropometry were assessed.

Results: One hundred and fourteen women (58 active, 56 placebo) completed the trial. The active-group compared with the placebo-group had significantly enhanced level of DHA in plasma phosphatidylcholine $(4.5 \%$ vs $3.8 \%, P=0.011)$, red blood cell phosphatidylcholine $(2.7 \%$ vs $2.2 \%, P=0.022)$ and phosphatidylethoanolamine (9.5\% vs $7.6 \%, P=0.002)$. There was no difference in cord plasma and red blood cell phospholipid DHA between the two groups. The neonates of the two groups of women had comparable anthropometric measurements at birth.

Conclusion: Daily supplementation of $600 \mathrm{mg}$ DHA enhances maternal but not fetal DHA status in pregnancy complicated by GDM. The inefficacy of the supplement to improve fetal status suggests that the transfer of DHA across the placenta maybe impaired in women with the condition. Regardless of the mechanisms responsible for the impairment of the transfer, the finding has implications for the management of neonates of women with GDM because they are born with a reduced level of DHA and the condition is thought to be associated with a risk of neuro-developmental deficits. We suggest that babies of women with GDM, particularly those not suckling, similar to the babies born prematurely require formula milk fortified with a higher level of DHA.
\end{abstract}

() 2015 Elsevier Ltd and European Society for Clinical Nutrition and Metabolism. All rights reserved.

\section{Introduction}

The impacts of gestational diabetes mellitus (GDM) on shortand long-term health of women and their offspring are increasingly

\footnotetext{
* Corresponding author. Lipidomics and Nutrition Research Centre, Faculty of Life Sciences and Computing, London Metropolitan University, 166-220 Holloway Road, London N7 8DB, UK. Tel.: +44 207133 2946; fax: +44 2071334682.

E-mail addresses: y.min@londonmet.ac.uk, minyoeju@gmail.com (Y. Min).
}

recognized [1]. In Europe, the estimated prevalence of GDM ranges from 2 to $6 \%$ and it is expected to rise with increasing obesity, a strong risk factor for developing the condition [2]. Other determinant factors are a family history of type 2 diabetes, advanced maternal age and ethnicity. Certain ethnic groups are more predisposed to GDM [3].

We have previously reported that GDM reduces the levels of docosahexaenoic acid (DHA) and arachidonic acid (AA) in maternal red blood cell $[4,5]$ and fetal red blood cell and plasma [5-7] 
phospholipids. DHA and AA, which are highly unsaturated fatty acids of the omega- 3 and omega- 6 family, respectively, are vital structural and functional components of cellular and sub-cellular membranes as well as precursors of diverse bioactive compounds. In addition, based on animal models of obesity and cell culture studies, it is postulated that DHA might be a potent anti-adiposity agent [8] and enhance glucose utilization by modulating insulin secretion and action $[9,10]$.

The importance of DHA and AA in fetal life has been extensively documented $[11,12]$. Of these two fatty acids, DHA is considered to be the most limiting nutrient in pregnancy and lactation because it is scarce or absent in land animal and plant food sources. Moreover, the synthesis of DHA from the parent compound $\alpha$-linolenic acid is inefficient. In normal pregnancy, DHA is preferentially transferred by placental selection from maternal to placental circulation. However, recent studies have reported that the placental uptake and transfer of DHA is impaired in pregnancy complicated by GDM $[13,14]$. There are no published communications whether or not the impact of this impairment could be ameliorated by DHA supplementation. In this report, we present the findings of a randomized, double-blind, placebo-controlled trial in which women with GDM were supplemented with DHA-enriched formula or high oleic acid sunflower seed oil. The primary outcome measure was the red blood cell membrane phospholipid DHA levels in the women and their neonates at delivery.

\section{Materials and methods}

The study was approved by East London \& The City HA Local Research Ethics Committee 3 (REC reference no. 06/Q0605/89) and registered with ISRCTN Register (registration no. ISRCTN68997518). Written informed consent was obtained from all participants and the investigation was carried out in accordance with the principles of the Declaration of Helsinki as revised in 2007. Participants, midwives, and all investigators were blinded to allocation until all the data collated and analyzed.

\subsection{Subjects and intervention}

The study was carried out in Newham Borough, an inner city area of Greater London with a high proportion of immigrant community, predominantly South Asian and African/Caribbean ethnic group. Subjects were recruited during their visit to the antenatal or diabetic clinics at Newham University Hospital between October 2007 and February 2012. The inclusion criteria were 17-45 years old women with singleton pregnancies diagnosed with GDM. Those who were planning to receive tocolytic or corticosteroid therapy or had been taking omega- 3 supplement during the period of time leading to their current pregnancy were excluded. Because of the high incidence of GDM and type 2 diabetes in the area, the hospital tests for GDM for women with high risk factors for the condition from early weeks of pregnancy. The test involves an overnight fast followed by drinking a solution of $75 \mathrm{~g}$ of glucose and drawing blood at 60 and $120 \mathrm{~min}$ for glucose determination. GDM is diagnosed if the glucose level at $120 \mathrm{~min}$ is greater than $7.8 \mathrm{mmol} / \mathrm{l}$.

The eligible women who consented to participate in the study were randomized to receive daily 2 capsules of either "DHAenriched formula" or "placebo (high oleic acid sunflower seed oil)". Each active supplement capsule contained $300 \mathrm{mg}$ of DHA, $42 \mathrm{mg}$ of eicosapentaenoic acid (EPA) and $8.4 \mathrm{mg}$ of AA, and placebo $721 \mathrm{mg}$ of oleic acid. Randomization was carried out using a random code generated by the supplement provider (Equazen/Vifor Pharma Ltd., Glattbrugg, Switzerland). Both supplements contained vitamin E (d-alpha tocopherol) as an antioxidant and were encapsulated in an identical oblong soft gelatin capsule (750 mg in size).

\subsection{Sample size}

Sample size was calculated based on our previous case-control study [7] which found a 35\% difference in red blood cell phosphatidylcholine DHA between neonates of pregnant women with GDM (4.0\%) and those without the condition (5.4\%). We assumed that supplementation of women with GDM with DHA-rich fish oil would increase the level of the nutrient in their neonates to the level of those born to women who had uncomplicated pregnancy. The power calculation indicated that a minimum of 40 subjects (neonates) per group would be required to detect the changes in red blood cell phosphatidylcholine DHA level with $80 \%$ power. The sample size and power calculation was performed using G*Power 3 [15] and based on a two independent groups, two-tailed t-test with an alpha of 0.05 .

\subsection{Blood collection and fatty acid analysis}

Non-fasting venous blood samples $(5-10 \mathrm{ml})$ were obtained from the subjects at recruitment $\left(17^{\text {th }}-33\right.$ rd gestational weeks) and delivery (maternal and cord) in EDTA vacutainer tubes. Samples collected during the day were transported promptly to the Lipidomics and Nutrition Research Centre (LNRC) laboratory for processing. Blood samples collected at night or on weekends were processed at the Pathology Laboratory, Newham University Hospital and subsequently transported to the LNRC laboratory. All samples were stored at $-70^{\circ} \mathrm{C}$ until analysis.

Fatty acid composition of red blood cell and plasma phospholipids was determined using the standardized method developed by our laboratory [7]. Briefly, total lipids were extracted by homogenizing the samples in chloroform and methanol, and the phospholipid fractions from the resulting total lipid were separated by thin-layer chromatography. Fatty acid methyl esters prepared from the phospholipids were separated using a gas-liquid chromatograph (HRGC MEGA 2 Series; Fisons Instruments, Milan, Italy) and quantified using a chromatography data system (Agilent EZChrom Elite Chromatography Data System v3.2, Scientific Software, Inc., Pleasanton, CA, USA).

\subsection{Neonatal anthropometric measurement}

Weight and length of the newborn babies were recorded by a midwife who attended the delivery as per routine practice and head-, shoulder-, mid-arm-, and abdominal circumferences by research midwives (JH and IN). Seca 210 portable measuring mat and Seca 201 ergonomic circumference measuring tape (Seca UK, Birmingham, UK) were used.

\subsection{Statistical analysis}

Data are presented as mean \pm standard deviation (SD), median (range), and number of occurrence as appropriate and statistical significance was set at $P<0.05$. All analyses were performed based on intention-to-treat principle. Independent t-test was used to compare the difference in fatty acids and anthropometric measurement between the active and placebo groups. The differences in pregnancy outcome were tested with Chi-square test. The change in DHA level within the group (baseline versus delivery) was assessed both by independent (including all subjects) and paired-sample (including only matched samples) t-test. All analyses were carried out with IBM SPSS Statistics version 20 (IBM Corporation, Armonk, NY, USA). 


\section{Results}

One hundred thirty eight women with GDM were randomized to receive either active or placebo, and 114 (58 active-group, 56 placebo-group) completed the trial (Fig. 1). The last delivery took place in May 2012.

The ethnic composition of the groups was similar and reflected the population diversity of the Borough (Table 1). $22.4 \%$ of the active-group and $25.4 \%$ of the placebo-group had gestational diabetes in their previous pregnancy. Over $60 \%$ of women were treated with oral hypoglycemic agents (active-group 49.3\%; placebo-group $50.7 \%$ ) or insulin (active-group $11.9 \%$; placebo-group $14.1 \%$ ). There was a wide variation in the duration of supplementation. This was a result of number of women being diagnosed with GDM either early or late stage of pregnancy. Five women (4 active and 1 placebo) claimed to have taken occasionally omega-3 supplement purchased from health shops during the course of the study. However, their DHA and EPA levels were not different from the mean values of their respective groups. Compliance was monitored by regular home visits by the research midwives and telephone contact (including out-of-office hour), and by counting unused capsules which the women are asked to bring with them when they come to collect the next batch of supplements.

Pregnancy outcomes and neonatal anthropometry are shown in Table 2. From the placebo-group, one woman had miscarriage and another delivered stillborn baby, and there was one case of cleft lip and palate in the active-group. There was no difference in the anthropometric measurement between the two groups. However, the numbers of babies born at preterm and low birth weight were higher in the active-group but the difference did not reach statistical significance level.

Percentages of the major fatty acids of plasma and red blood cell phosphatidylcholine and red blood cell phosphatidylethanolamine are presented in Table 3. There was no difference in fatty acid composition of plasma or red blood cell phospholipids between those randomized to receive active supplement or placebo at baseline. At delivery, the women supplemented with active supplement compared with those who were given placebo had higher level of DHA in plasma phosphatidylcholine $(P=0.011)$, red blood cell phosphatidylcholine $(P=0.022)$ and phosphatidylethanolamine $(P=0.002)$, and a lower level of AA in plasma phosphatidylcholine $(P=0.045)$. Both groups had comparable levels of saturated and monounsaturated fatty acids in plasma and red blood cell phospholipids. Moreover, they had a similar red blood cell unsaturation index (sum of the \% unsaturated fatty acids multiplied by their number of double bonds).

Within-group baseline and delivery comparison in plasma phosphatidylcholine revealed an increase in palmitic $(P<0.01)$ and oleic $(P<0.001)$ acids and decrease in stearic acid $(P<0.001)$ in both groups. There was a decrease in the level of DHA in the placebo-group $(-17.4 \%, P=0.009)$ and $A A$ in the active-group $(-12.3 \%, P=0.000)$. The level of DHA in the active-group and AA in the placebo-group did not change between baseline and delivery.

In red blood cell phosphatidylcholine, oleic and stearic acids in the active-group $(P<0.05)$ and $\alpha$-linolenic acid, EPA, DHA in the placebo-group $(P<0.01)$ decreased between baseline and delivery. The changes in red blood cell phosphatidylethanolamine fatty acids with the progress of pregnancy mirrored broadly that of plasma phosphatidylcholine. There was an increase in saturated $(P<0.05)$ and monounsaturated $(P<0.01)$ fatty acids, and a decrease in AA $(P<0.01)$ in both groups of women. The level of EPA and DHA did not change between baseline and delivery in the women who were given active supplement. In contrast, the level of both fatty acids decreased significantly at delivery in those who received placebo $(P=0.001)$. These changes led to a reduced unsaturation index $(P<0.01)$ in both groups.

Plasma and red blood cell phospholipid fatty acid profiles of the neonates from both groups were similar (Table 4). Within the active

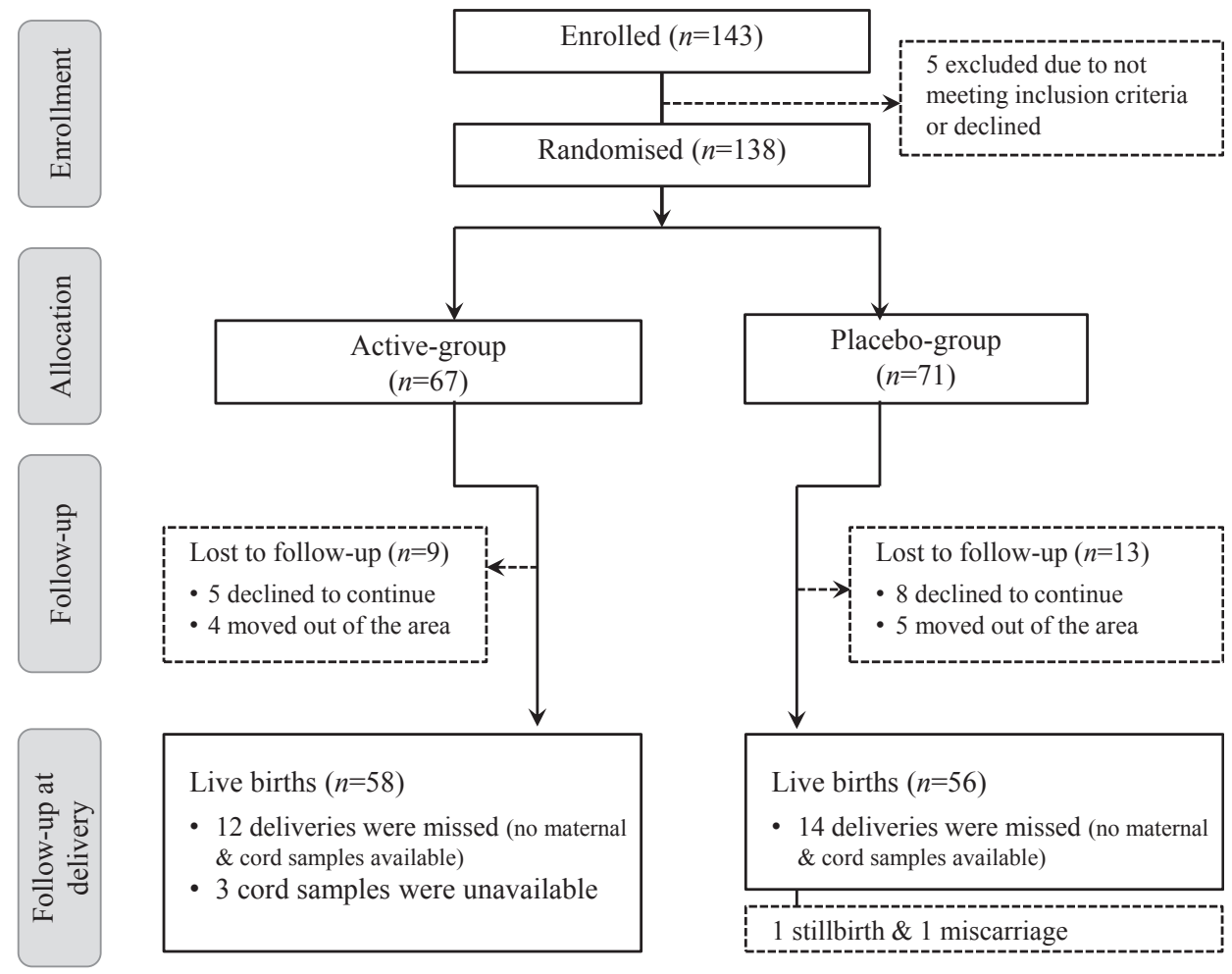

Fig. 1. Flowchart of participants during the course of the randomized trial. 
Table 1

Demographic and obstetric characteristics of the participants.

\begin{tabular}{|c|c|c|}
\hline & Active-group & Placebo-group \\
\hline Number of participants $(n)$ & 67 & 71 \\
\hline Gestation at recruitment (weeks) ${ }^{\mathrm{b}}$ & $28.3(17.4-33.4)$ & $28.3(17.0-32.9)$ \\
\hline Age (years) ${ }^{\mathrm{b}}$ & $31.0(21.0-41.0)$ & $32.0(21.0-44.0)$ \\
\hline Pre-pregnancy weight $(\mathrm{kg})^{\mathrm{c}}$ & $73.9 \pm 15.8$ & $72.6 \pm 15.3$ \\
\hline Height $(\mathrm{m})^{\mathrm{c}}$ & $1.6 \pm 0.1$ & $1.6 \pm 0.1$ \\
\hline Pre-pregnancy $\mathrm{BMI}^{\mathrm{c}, \mathrm{d}}$ & $29.0 \pm 5.6$ & $29.2 \pm 5.7$ \\
\hline$\leq 25.0$ & 17 & 19 \\
\hline$\overline{25} .1-30.0$ & 23 & 24 \\
\hline$\geq 30.1$ & 27 & 28 \\
\hline \multicolumn{3}{|l|}{ Ethnicity $(n)^{\mathrm{e}}$} \\
\hline Asian & 40 & 44 \\
\hline African/Afro-Caribbean & 18 & 18 \\
\hline Caucasian & 5 & 5 \\
\hline Others & 4 & 4 \\
\hline \multicolumn{3}{|l|}{ Parity $(n)^{\mathrm{f}}$} \\
\hline 0 & 33 & 24 \\
\hline $1-3$ & 27 & 40 \\
\hline$\geq 4$ & 6 & 5 \\
\hline Smoker $(n)$ & 2 & 0 \\
\hline Planned pregnancy $(n)$ & 42 & 37 \\
\hline GDM in previous pregnancy $(n)$ & 15 & 18 \\
\hline Folic acid use $(n)$ & 18 & 18 \\
\hline \multicolumn{3}{|l|}{ Glucose tolerance test } \\
\hline Gestation $\left(\right.$ weeks) ${ }^{\mathrm{b}}$ & $18.7(11.4-30.1)$ & $20.6(13.3-31.9)$ \\
\hline Glucose at $0 \mathrm{~min}(\mathrm{mmol})^{\mathrm{c}}$ & $5.6 \pm 1.6$ & $5.5 \pm 1.3$ \\
\hline Glucose at $120 \mathrm{~min}(\mathrm{mmol})^{\mathrm{c}}$ & $9.6 \pm 2.2$ & $9.3 \pm 1.8$ \\
\hline \multicolumn{3}{|l|}{ Diabetes treatment $(n)$} \\
\hline Diet only & 26 & 24 \\
\hline Oral hypoglycemic agents & 33 & 36 \\
\hline Insulin & 8 & 10 \\
\hline Oral hypoglycemic agents + insulin & - & 1 \\
\hline \multicolumn{3}{|l|}{ Family history of diabetes $(n)$} \\
\hline Mother & 29 & 21 \\
\hline Father & 20 & 26 \\
\hline Both parent & 6 & 12 \\
\hline
\end{tabular}

${ }^{\mathrm{a}}$ No statistical test was performed as per CONSORT guidelines.

b Gestation week and age are presented as median ( $\min -\max$ ).

c Values are presented as mean $\pm \mathrm{SD}$.

d BMI, body mass index $\left(\mathrm{kg} / \mathrm{m}^{2}\right)$.

e The UK Home Office's classification for an individual's ethnicity according to person's self-definition was used; Asian (Bangladesh, Bengali, Sri Lankan, Indian Pakistani), African/Afro-Caribbean (Black African, Black British, Caribbean, AfroCaribbean), Caucasian (English, Polish, Irish, European), Others (Filipino, Arab, North African, Latin American, Mixed-race).

${ }^{\mathrm{f}}$ Information was not available from 3 women (1 active-group, 2 placebo-group).

supplemented group, the level of DHA in the neonates whose mothers had less than 10 weeks of supplement did not differ from those supplemented for a longer period.

\section{Discussion}

Mature red blood cells have a limited ability of synthesizing phospholipids de novo from glycerol or sphingosine backbone. Therefore, the renewal/remodeling of red blood cell membrane phospholipids, which occurs continuously, is reliant on plasma lipid pool. The renewal mechanisms include transfer of fatty acids from plasma neutral lipids to phosphatidylethanolamine through phosphatidylcholine [16], deacylation-reacylation cycles of endogenous fatty acids and passive exchange of intact phospholipids, primarily phosphatidylcholine, with plasma phospholipids [17]. Hence, it is evident that the fatty acid moieties of red blood cell phospholipids have their origin in plasma lipids [18] in individuals without underlining clinical conditions.

We have previously observed that women with GDM, regardless of their ethnic origin and dietary background, had reduced level of DHA in red blood cell but not plasma phospholipids [4,5,7]. These findings led us to postulate "the incorporation of DHA from plasma
Table 2

Pregnancy outcomes and anthropometric measurement.

\begin{tabular}{|c|c|c|c|}
\hline & & Active-group & Placebo-group ${ }^{\mathrm{b}}$ \\
\hline \multicolumn{2}{|l|}{ Live births $(n)^{\mathrm{c}}$} & 58 & 56 \\
\hline \multicolumn{2}{|c|}{ Gestation at delivery (weeks) ${ }^{\mathrm{d}}$} & $38.1(33.3-41.1)$ & $38.1(35.9-41.1)$ \\
\hline \multicolumn{2}{|c|}{ Supplementation duration (weeks) ${ }^{\mathrm{d}}$} & $10.0(4.0-22.0)$ & $10.0(4.0-20.0)$ \\
\hline \multicolumn{4}{|c|}{ Gender $(n)$} \\
\hline \multicolumn{2}{|l|}{ Male } & 29 & 32 \\
\hline \multicolumn{2}{|l|}{ Female } & 29 & 24 \\
\hline \multicolumn{4}{|l|}{ Delivery method $(n)$} \\
\hline \multirow[t]{3}{*}{ Vaginal - } & Spontaneous & 19 & 11 \\
\hline & Assisted & 5 & 3 \\
\hline & Induced & 6 & 13 \\
\hline \multirow[t]{2}{*}{ Caesarean section - } & Elective & 7 & 9 \\
\hline & Emergency & 21 & 20 \\
\hline \multicolumn{2}{|l|}{ Preterm birth $(n)^{\mathrm{e}}$} & 12 & 5 \\
\hline \multicolumn{2}{|l|}{ Late-preterm birth $(n)^{\mathrm{f}}$} & 10 & 5 \\
\hline \multicolumn{2}{|l|}{ Low birth weight $(n)^{g}$} & 8 & 4 \\
\hline \multicolumn{2}{|l|}{ Macrosomia $(n)^{\mathrm{h}}$} & 3 & 3 \\
\hline \multicolumn{2}{|c|}{ Neonatal hypoglycemia $(n)$} & 2 & 3 \\
\hline \multicolumn{2}{|l|}{ Congenital defect $(n)^{\mathrm{i}}$} & 1 & 0 \\
\hline \multicolumn{4}{|c|}{ Anthropometric measurement ${ }^{\mathrm{j}}$} \\
\hline \multicolumn{2}{|l|}{ Weight (kg) } & $3.2 \pm 0.6$ & $3.1 \pm 0.4$ \\
\hline \multicolumn{2}{|l|}{ Length $(\mathrm{cm})$} & $49.0 \pm 7.8$ & $50.3 \pm 5.7$ \\
\hline \multicolumn{2}{|c|}{ Head circumference $(\mathrm{cm})$} & $33.9 \pm 1.6$ & $33.8 \pm 2.5$ \\
\hline \multicolumn{2}{|c|}{ Shoulder circumference $(\mathrm{cm})$} & $36.3 \pm 5.5$ & $36.0 \pm 5.6$ \\
\hline \multicolumn{2}{|c|}{ Mid-arm circumference $(\mathrm{cm})$} & $11.9 \pm 2.1$ & $11.5 \pm 2.6$ \\
\hline \multicolumn{2}{|c|}{ Abdominal circumference $(\mathrm{cm})$} & $33.1 \pm 4.1$ & $33.0 \pm 4.3$ \\
\hline
\end{tabular}

a The pregnancy outcome and neonatal anthropometric measurement did not differ between active and placebo groups.

b There was one stillbirth and one miscarriage in the placebo-group.

c This number included all the subjects who completed the supplementation regardless of the availability of blood samples at delivery.

${ }^{\mathrm{d}}$ Gestation week at delivery and supplementation duration are given median $(\min -\max )$.

e Preterm birth; born less than 37 weeks of gestation.

${ }^{f}$ Late-preterm birth; born between 34 0/7 weeks and 36 6/7 weeks of gestation.

g Low birth weight; birth weight less than $2.5 \mathrm{~kg}$.

h Macrosomia; body weight greater than $4 \mathrm{~kg}$.

${ }^{i}$ One baby from the active-group was born with cleft lip and palate.

j Anthropometric measurement are presented as mean \pm SD. The measurement for one baby from the active-group was not obtained.

into red blood cells is compromised in women with the condition due to hyperglycemia". In addition, we postulated "this impairment is ameliorated by a rigorous glycemic control". Consistent with our postulation, DHA supplementation enriched the level of the fatty acid in plasma and red blood cell phospholipids in the GDM women whose blood glucose was well-controlled by using diet, oral hypoglycemic agents or/and insulin.

Maternal DHA level declines in the later part of pregnancy in healthy "well-nourished" women without obstetric complications. This is often described as a physiological response to pregnancy. There was no such decrease in the women with gestational diabetes supplemented with DHA-enriched formula. Moreover, the phenomenon does not occur in pregnant women from communities who consume high amounts of fish and seafood [19], or in those supplemented with fish oil or fish [20,21]. Hence, the decline of DHA in pregnancy signifies an imbalance between maternal status and mother-fetus requirement.

Working groups have recommended that expectant and nursing mothers have to consume $300 \mathrm{mg}$ of DHA daily [22]. The recommended value which is based on breast milk, and maternal, neonatal and infant blood DHA data from supplemented and unsupplmented women primarily from the developed countries are essentially guesstimates. In our study of a cohort of unsupplmented pregnant British and Sudanese women, the levels of DHA in maternal plasma phosphatidylcholine were $4.3 \%$ [7] and $2.3 \%$ (Nyuar KB and Ghebremeskel K, unpublished data) respectively. 
Table 3

Maternal plasma and red blood cell phospholipid fatty acid composition at baseline and delivery.

\begin{tabular}{|c|c|c|c|c|c|c|c|c|}
\hline & \multicolumn{3}{|l|}{ Baseline } & \multicolumn{3}{|l|}{ Delivery } & \multicolumn{2}{|c|}{ Baseline $v s$ delivery ${ }^{\mathrm{C}}(P$ value) } \\
\hline & Active-group ( $n$ 67) & Placebo-group ( $n$ 71) & $P$ value ${ }^{\mathrm{b}}$ & Active-group ( $n$ 46) & Placebo-group ( $n$ 42) & $P$ value $^{\mathrm{b}}$ & Active-group & Placebo-group \\
\hline \multicolumn{9}{|c|}{ Plasma phosphatidylcholine } \\
\hline Palmitic & $29.8 \pm 3.6$ & $30.4 \pm 3.1$ & NS & $32.0 \pm 2.1$ & $32.7 \pm 2.6$ & NS & 0.000 & 0.000 \\
\hline Stearic & $10.2 \pm 1.4$ & $10.0 \pm 1.2$ & NS & $9.1 \pm 1.0$ & $9.0 \pm 1.2$ & NS & 0.000 & 0.000 \\
\hline Oleic & $10.9 \pm 3.8$ & $10.7 \pm 2.0$ & NS & $13.0 \pm 2.4$ & $13.0 \pm 2.6$ & NS & 0.001 & 0.000 \\
\hline Linoleic & $24.7 \pm 3.5$ & $24.8 \pm 3.0$ & NS & $23.7 \pm 3.0$ & $22.7 \pm 3.6$ & NS & NS & 0.002 \\
\hline$\alpha$-linolenic & $0.3 \pm 0.1$ & $0.3 \pm 0.1$ & NS & $0.4 \pm 0.1$ & $0.3 \pm 0.1$ & NS & NS & NS \\
\hline Arachidonic & $10.6 \pm 2.1$ & $10.6 \pm 1.9$ & NS & $9.3 \pm 1.8$ & $10.1 \pm 2.3$ & 0.045 & 0.000 & NS \\
\hline Eicosapentaenoic & $0.7 \pm 0.7$ & $0.8 \pm 0.7$ & NS & $0.7 \pm 0.4$ & $0.6 \pm 0.5$ & NS & NS & NS \\
\hline Docosahexaenoic & $4.5 \pm 1.0$ & $4.6 \pm 1.5$ & NS & $4.5 \pm 1.0$ & $3.8 \pm 1.2$ & 0.011 & NS & 0.009 \\
\hline$\Sigma$ Saturates & $41.0 \pm 3.4$ & $41.3 \pm 2.5$ & NS & $42.0 \pm 1.9$ & $42.6 \pm 2.4$ & NS & NS & 0.006 \\
\hline$\Sigma$ Monoenes & $11.5 \pm 4.0$ & $11.4 \pm 2.1$ & NS & $13.9 \pm 2.5$ & $13.9 \pm 2.7$ & NS & 0.001 & 0.000 \\
\hline$\Sigma \mathrm{n}-6$ & $40.4 \pm 3.4$ & $40.0 \pm 3.5$ & NS & $37.2 \pm 2.8$ & $37.2 \pm 4.0$ & NS & 0.000 & 0.000 \\
\hline$\Sigma \mathrm{n}-3$ & $6.1 \pm 1.5$ & $6.3 \pm 2.3$ & NS & $6.0 \pm 1.4$ & $5.3 \pm 1.7$ & 0.031 & NS & 0.015 \\
\hline$\Sigma$ n-6/ $\Sigma$ n-3 ratio & $7.1 \pm 1.9$ & $7.3 \pm 3.4$ & NS & $6.5 \pm 1.9$ & $7.9 \pm 3.4$ & 0.028 & NS & NS \\
\hline \multicolumn{9}{|c|}{ Red blood cell phosphatidylcholine } \\
\hline Palmitic & $36.4 \pm 2.3$ & $36.3 \pm 3.4$ & NS & $35.8 \pm 4.0$ & $36.4 \pm 4.3$ & NS & NS & NS \\
\hline Stearic & $8.1 \pm 1.2$ & $8.1 \pm 1.6$ & NS & $8.3 \pm 1.5$ & $8.5 \pm 1.7$ & NS & 0.018 & NS \\
\hline Oleic & $15.5 \pm 1.6$ & $15.5 \pm 2.3$ & NS & $16.9 \pm 2.3$ & $17.0 \pm 2.8$ & NS & 0.000 & 0.000 \\
\hline Linoleic & $22.5 \pm 2.8$ & $21.8 \pm 3.7$ & NS & $22.4 \pm 3.3$ & $21.2 \pm 4.2$ & NS & NS & NS \\
\hline$\alpha$-linolenic & $0.2 \pm 0.1$ & $0.2 \pm 0.1$ & NS & $0.2 \pm 0.1$ & $0.2 \pm 0.1$ & NS & NS & 0.007 \\
\hline Arachidonic & $7.2 \pm 1.5$ & $7.5 \pm 2.0$ & NS & $6.8 \pm 1.8$ & $7.3 \pm 2.7$ & NS & NS & NS \\
\hline Eicosapentaenoic & $0.4 \pm 0.4$ & $0.6 \pm 0.5$ & NS & $0.5 \pm 0.3$ & $0.4 \pm 0.3$ & NS & NS & 0.003 \\
\hline Docosahexaenoic & $2.5 \pm 0.7$ & $2.7 \pm 1.0$ & NS & $2.7 \pm 1.0$ & $2.2 \pm 1.0$ & 0.022 & NS & 0.002 \\
\hline$\Sigma$ Saturates & $45.5 \pm 2.2$ & $45.3 \pm 3.6$ & NS & $44.9 \pm 4.1$ & $45.7 \pm 4.5$ & NS & NS & NS \\
\hline$\Sigma$ Monoenes & $16.1 \pm 1.7$ & $16.2 \pm 2.3$ & NS & $17.6 \pm 2.3$ & $17.7 \pm 3.0$ & NS & 0.000 & 0.000 \\
\hline$\Sigma \mathrm{n}-6$ & $33.4 \pm 2.7$ & $33.0 \pm 4.1$ & NS & $32.7 \pm 4.5$ & $32.0 \pm 5.9$ & NS & NS & 0.036 \\
\hline$\Sigma \mathrm{n}-3$ & $3.6 \pm 1.0$ & $4.0 \pm 1.5$ & NS & $3.8 \pm 1.3$ & $3.2 \pm 1.4$ & 0.044 & NS & 0.000 \\
\hline$\Sigma$ n-6/ $\Sigma$ n-3 ratio & $10.3 \pm 5.0$ & $9.7 \pm 4.5$ & NS & $9.6 \pm 3.4$ & $11.6 \pm 4.7$ & 0.03 & NS & 0.023 \\
\hline Unsaturation index ${ }^{\mathrm{d}}$ & $121.5 \pm 8.2$ & $123.3 \pm 14.7$ & NS & $121.5 \pm 15.7$ & $118.1 \pm 19.1$ & NS & NS & 0.036 \\
\hline \multicolumn{9}{|c|}{ Red blood cell phosphatidylethanolamine } \\
\hline Palmitic & $14.9 \pm 1.6$ & $14.9 \pm 1.8$ & NS & $15.9 \pm 2.8$ & $16.5 \pm 3.7$ & NS & 0.02 & 0.004 \\
\hline Stearic & $5.5 \pm 0.9$ & $5.6 \pm 1.1$ & NS & $6.3 \pm 1.3$ & $6.5 \pm 1.7$ & NS & 0.000 & 0.003 \\
\hline Oleic & $16.4 \pm 1.2$ & $16.4 \pm 1.4$ & NS & $17.9 \pm 2.9$ & $18.6 \pm 4.5$ & NS & 0.004 & 0.009 \\
\hline Linoleic & $5.5 \pm 1.2$ & $5.6 \pm 1.4$ & NS & $6.0 \pm 1.4$ & $6.1 \pm 1.6$ & NS & 0.02 & NS \\
\hline$\alpha$-linolenic & $0.2 \pm 0.1$ & $0.2 \pm 0.1$ & NS & $0.2 \pm 0.1$ & $0.2 \pm 0.1$ & NS & NS & NS \\
\hline Arachidonic & $19.7 \pm 2.4$ & $19.4 \pm 2.6$ & NS & $17.7 \pm 3.3$ & $17.7 \pm 4.1$ & NS & 0.000 & 0.002 \\
\hline Eicosapentaenoic & $0.9 \pm 0.5$ & $1.0 \pm 0.7$ & NS & $0.9 \pm 0.6$ & $0.8 \pm 0.7$ & NS & NS & 0.001 \\
\hline Docosahexaenoic & $8.8 \pm 1.9$ & $9.2 \pm 2.2$ & NS & $9.5 \pm 2.3$ & $7.6 \pm 3.0$ & 0.002 & NS & 0.001 \\
\hline$\Sigma$ Saturates & $21.3 \pm 2.7$ & $21.3 \pm 1.6$ & NS & $23.2 \pm 4.0$ & $24.0 \pm 5.3$ & NS & 0.001 & 0.001 \\
\hline$\Sigma$ Monoenes & $16.9 \pm 1.3$ & $17.0 \pm 1.5$ & NS & $18.5 \pm 2.9$ & $19.2 \pm 4.5$ & NS & 0.004 & 0.011 \\
\hline$\Sigma \mathrm{n}-6$ & $33.5 \pm 3.5$ & $33.4 \pm 4.2$ & NS & $31.1 \pm 4.6$ & $31.6 \pm 6.6$ & NS & 0.000 & 0.003 \\
\hline$\Sigma \mathrm{n}-3$ & $13.6 \pm 2.7$ & $14.0 \pm 3.4$ & NS & $13.7 \pm 3.2$ & $11.7 \pm 4.5$ & 0.028 & NS & 0.001 \\
\hline$\Sigma$ n-6/ $\Sigma$ n-3 ratio & $2.6 \pm 0.7$ & $2.6 \pm 1.1$ & NS & $2.4 \pm 0.7$ & $3.5 \pm 3.9$ & NS & 0.047 & NS \\
\hline Unsaturation index ${ }^{\mathrm{d}}$ & $215.2 \pm 12.5$ & $217.6 \pm 13.0$ & NS & $207.1 \pm 24.5$ & $198.7 \pm 33.6$ & NS & 0.009 & 0.000 \\
\hline
\end{tabular}

The corresponding values in cord were $7.1 \%$ and $3.3 \%$. The question is whether supplementation of Sudanese pregnant women with $300 \mathrm{mg}$ of DHA daily would be sufficient to forestall the decline of the fatty acid in late pregnancy. We suggest that the DHA requirement for healthy pregnant women should be based on the amount needed to prevent this decline.

Improved neonatal DHA status after maternal supplementation with high DHA during uncomplicated pregnancies has been consistently reported. Similarly, we have recently reported maternal supplementation-induced enrichment of cord blood DHA in pregnancy complicated by type 2 diabetes [23]. In this study, the neonates of the DHA supplemented women did not have increased level of the nutrient. The reason for this intriguing finding is not clear since type 2 and GDM share similar metabolic features and both groups of women were given $600 \mathrm{mg}$ of DHA daily. However, impaired placental uptake $[13,14]$ and maternal-fetal transfer [14] of DHA, and considerable placental abnormalities than in type 1 and 2 diabetes [24] have been reported in pregnancy complicated by GDM. It is worth noting that the shorter supplementation duration (median 10 weeks) in the current study compared with our previous investigation of pregnant women with type 2 diabetes (median 26 weeks) [23] could be germane to the outcome.

As in our previous studies [4,5], there was a significant decline in the level of AA in red blood cell phosphatidylcholine in both groups of women between diagnosis and delivery. Although the DHAenriched supplement contained about $2 \%$ of AA (\% total fatty acids), there was a similar decrease in plasma phosphatidylcholine $A A$ in the group who received DHA-enriched supplement. The DHA + EPA/AA ratio of the capsule was 26:1 and there is evidence that supplementation-induced increase in tissue level of DHA, EPA or DHA plus EPA is associated with a concomitant decrease in AA [25]. Hence, it appears that AA in both plasma and red blood cell 
Table 4

Neonatal plasma and red blood cell phospholipid fatty acid composition.,

\begin{tabular}{|c|c|c|c|c|c|c|}
\hline & \multicolumn{2}{|c|}{ Plasma phosphatidylcholine } & \multicolumn{2}{|c|}{ Red blood cell phosphatidylcholine } & \multicolumn{2}{|c|}{$\begin{array}{l}\text { Red blood cell } \\
\text { phosphatidylethanolamine }\end{array}$} \\
\hline & Active-group & Placebo-group & Active-group & Placebo-group & Active-group & Placebo-group \\
\hline Palmitic & $30.3 \pm 2.3$ & $30.3 \pm 2.1$ & $36.8 \pm 2.5$ & $36.5 \pm 2.9$ & $17.8 \pm 2.9$ & $17.4 \pm 2.6$ \\
\hline Stearic & $13.4 \pm 1.8$ & $13.3 \pm 1.5$ & $9.2 \pm 1.4$ & $9.6 \pm 1.5$ & $6.1 \pm 1.7$ & $5.8 \pm 1.2$ \\
\hline Oleic & $12.0 \pm 1.9$ & $11.8 \pm 1.9$ & $18.2 \pm 2.2$ & $17.6 \pm 1.9$ & $13.8 \pm 3.0$ & $13.4 \pm 2.5$ \\
\hline Linoleic & $10.3 \pm 2.3$ & $9.9 \pm 2.6$ & $9.3 \pm 2.2$ & $8.9 \pm 1.4$ & $2.5 \pm 0.6$ & $2.4 \pm 0.5$ \\
\hline$\alpha$-linolenic & $0.1 \pm 0.1$ & $0.1 \pm 0.1$ & $0.1 \pm 0.1$ & $0.1 \pm 0.03$ & $0.1 \pm 0.03$ & $0.1 \pm 0.04$ \\
\hline Arachidonic & $16.9 \pm 3.0$ & $18.0 \pm 3.4$ & $13.4 \pm 2.6$ & $14.3 \pm 2.6$ & $23.8 \pm 3.9$ & $24.4 \pm 3.0$ \\
\hline Eicosapentaenoic & $0.5 \pm 0.3$ & $0.5 \pm 0.4$ & $0.3 \pm 0.2$ & $0.3 \pm 0.3$ & $0.3 \pm 0.2$ & $0.3 \pm 0.3$ \\
\hline Docosahexaenoic & $5.8 \pm 1.7$ & $5.5 \pm 1.7$ & $3.5 \pm 1.2$ & $3.4 \pm 1.1$ & $8.4 \pm 1.9$ & $8.2 \pm 1.6$ \\
\hline$\Sigma$ Saturates & $44.5 \pm 2.3$ & $44.4 \pm 2.3$ & $46.9 \pm 2.8$ & $47.0 \pm 2.4$ & $25.5 \pm 3.7$ & $24.7 \pm 2.4$ \\
\hline$\Sigma$ Monoenes & $13.0 \pm 2.2$ & $12.7 \pm 2.0$ & $19.2 \pm 2.4$ & $18.5 \pm 2.0$ & $14.4 \pm 3.1$ & $13.9 \pm 2.6$ \\
\hline$\Sigma \mathrm{n}-6$ & $34.2 \pm 3.3$ & $34.8 \pm 3.1$ & $28.0 \pm 3.9$ & $28.6 \pm 3.4$ & $35.9 \pm 4.3$ & $37.3 \pm 4.0$ \\
\hline$\Sigma \mathrm{n}-3$ & $6.9 \pm 1.9$ & $6.7 \pm 2.0$ & $4.2 \pm 1.4$ & $4.2 \pm 1.3$ & $9.8 \pm 2.3$ & $9.7 \pm 2.2$ \\
\hline$\Sigma n-6 / \Sigma n-3$ ratio & $5.4 \pm 1.6$ & $5.7 \pm 2.2$ & $7.5 \pm 2.9$ & $7.5 \pm 2.7$ & $3.9 \pm 1.3$ & $4.1 \pm 1.2$ \\
\hline Unsaturation index ${ }^{c}$ & & & $134.3 \pm 16.5$ & $136.5 \pm 13.6$ & $213.2 \pm 21.6$ & $217.4 \pm 16.7$ \\
\hline
\end{tabular}

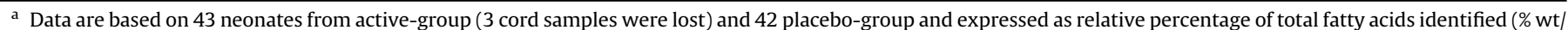
wt).

b No statistically significant differences were found between the two groups when tested with an independent t-test.

${ }^{c}$ Unsaturation index is the sum of the \% unsaturated fatty acids multiplied by their number of double bonds.

phospholipids was displaced, to a certain extent, by DHA and EPA. The significance of reduction in blood AA level in women compromised by GDM is yet to be fully investigated. However, because $\mathrm{AA}$ is a ubiquitous constituent of most tissues and plays an important role in biological functions under normal physiological conditions, there may be a need to provide AA in order to help prevent the decline.

Nutritional intervention and epidemiological studies have reported that increased intake of long-chain omega-3 fatty acids during pregnancy reduces preterm births by prolonging gestation period [26-29]. We have observed a similar trend in a small number of pregnant women with type 2 diabetes [23]. Paradoxically, in the current study, the number of preterm births was higher (statistically insignificant) in the active-group. To find possible explanations for the observation, past obstetrics histories of the women who delivered prematurely were examined. In the activegroup, 8 of the 12 women who delivered early had obstetric complications (pregnancy-induced hypertension, GDM, miscarriages) in their previous pregnancies. There was only one woman who had a history of GDM in the placebo-group. Hence, it is possible that the higher number of preterm births in the active-group may have been a reflection of the predisposition of these women to a recurrent preterm delivery due to genetic-environmental factors or unidentified underlying medical conditions.

There is indication that the provision of DHA during pre and postnatal period influences adiposity in infants [30,31] and preschool children [32,33]. We have assessed whether a similar effect was apparent in this study. Shoulder, mid-arm and abdomen circumference measurements were used as an indirect indictor of adiposity. There was no difference in the values of the aforementioned parameters between the neonates born to the two groups of mothers. This finding was not surprising because maternal supplementation did not enhance fetal DHA status.

There was a high number of a delivery sample loss resulting from unanticipated births before due date, women moving out of the area without providing a contact address and too-busy labor or delivery midwives to collect samples. This limitation would have been minimized by recruiting additional midwives but it could not be done because of financial constraints. Another limitation was the inability to determine placental fatty acids and the activity and expression of placental fatty acid binding and transport proteins. Lastly, despite our efforts to obtain information about a habitual diet of the women using a 4-day food diary, we were unable to extract valuable data about their nutritional intake. This was because a large number of diaries were returned incomplete.

This randomized, double-blind, placebo-controlled study demonstrates that supplementation of women with GDM is effective in enhancing maternal but not fetal DHA status. The failure of the supplementation to improve the level of fetal DHA is of some concern because the offspring of women with GDM are born with a lower level of the nutrient and the condition is thought to be associated with a risk of neuro-developmental deficits. It is plausible that maternal supplementation with more than $600 \mathrm{mg}$ of DHA may trickle down to the fetus and mitigate the insufficiency. Regardless, we suggest that babies of women with GDM, particularly those not suckling, similar to the babies born prematurely require formula milk fortified with a higher level of DHA.

\section{Statement of authorship}

YM and KG conceived the idea and designed the study. OD contributed clinical aspect of the study design. YM prepared the protocols, performed data analysis and its interpretation and drafted the manuscript. KG contributed to the interpretation of findings. JH and IN recruited and followed up the patients, collected biological samples and clinical and demographic information relevant to the study. SE and ASB carried out sample processing and fatty acid analysis. All authors approved the final manuscript.

\section{Funding sources}

The study was supported by research grants from FP6 Marie Curie Actions-Transfer of Knowledge (MTKD-CT-2005-029914), Foyle Foundation, Newham University Hospital NHS Trust, Diabetes Research Network (North East London Diabetes Local Research Network), Equazen/Vifor Pharma Ltd., London Metropolitan University, Sir Halley Stewart Trust, The Mother and Child Foundation, Letten Foundation and personal donation from Emeritus Professor Clara Lowy. The supplements (Mumomega ${ }^{\circledR}$ and placebo) used in this study were prepared and provided by Equazen/Vifor Pharma Ltd. free of charge. The funding organizations and supplement supplier played no role in the design of the study, analysis, interpretation of data, or preparation of the manuscript. 


\section{Conflict of interest statement}

All authors declare that there is no competing financial interest in relation to this work.

\section{Acknowledgments}

The authors thank all the women and their families for participating in the study, Vasu Chauhan and her staffs at the Pathology Laboratory (Newham University Hospital) for processing night delivery samples, the midwives and staffs at the Maternity Services (Newham University Hospital) for their valuable assistance in the recruitment and delivery sample collection, Ambreen Solangi for her administrative assistance and Katia Mariniello and Amanda Hallot for their contribution to the sample processing during the initial stage of the study.

\section{References}

[1] Yessoufou A, Moutairou K. Maternal diabetes in pregnancy: early and longterm outcomes on the offspring and the concept of "metabolic memory. Exp Diabetes Res 2011:2011:218598.

[2] Buckley BS, Harreiter J, Damm P, Corcoy R, Chico A, Simmons D, et al., DALI Core Investigator Group. Gestational diabetes mellitus in Europe: prevalence, current screening practice and barriers to screening. A review. Diabet Med 2012;29(7):844-54.

[3] Green JR, Pawson IG, Schumacher LB, Perry J, Kretchmer N. Glucose tolerance in pregnancy: ethnic variation and influence of body habitus. Am J Obstet Gynecol 1990;163(1 Pt 1):86-92.

[4] Min Y, Ghebremeskel K, Lowy C, Thomas B, Crawford MA. Adverse effect of obesity on red cell membrane arachidonic and docosahexaenoic acids in gestational diabetes. Diabetologia 2004;47(1):75-81.

[5] Min Y, Nam JH, Ghebremeskel K, Kim A, Crawford M. A distinctive fatty acid profile in circulating lipids of Korean gestational diabetics: a pilot study. Diabetes Res Clin Pract 2006;73(2):178-83.

[6] Wijendran V, Bendel RB, Couch SC, Philipson EH, Cheruku S, Lammi-Keefe C]. Fetal erythrocyte phospholipid polyunsaturated fatty acids are altered in pregnancy complicated with gestational diabetes mellitus. Lipids 2000;35(8): 927-31.

[7] Min Y, Lowy C, Ghebremeskel K, Thomas B, Bitsanis D, Crawford MA. Fetal erythrocyte membrane lipids modification: preliminary observation of an early sign of compromised insulin sensitivity in offspring of gestational diabetic women. Diabet Med 2005;22(7):914-20.

[8] Ruzickova J, Rossmeisl M, Prazak T, Flachs P, Sponarova J, Veck M, et al. Omega-3 PUFA of marine origin limit diet-induced obesity in mice by reducing cellularity of adipose tissue. Lipids 2004;39(12):1177-85.

[9] González-Périz A, Horrillo R, Ferré N, Gronert K, Dong B, Morán-Salvador E, et al. Obesity-induced insulin resistance and hepatic steatosis are alleviated by omega-3 fatty acids: a role for resolvins and protectins. FASEB J 2009;23(6): 1946-57.

[10] Ramanadham S, Zhang S, Ma Z, Wohltmann M, Bohrer A, Hsu FF, et al. Delta6-, stearoyl CoA-, and Delta5-desaturase enzymes are expressed in beta-cells and are altered by increases in exogenous PUFA concentrations. Biochim Biophys Acta 2002:1580(1):40-56.

[11] Uauy R, Mena P, Rojas C. Essential fatty acids in early life: structural and functional role. Proc Nutr Soc 2000;59(1):3-15.

[12] Koletzko B, Agostoni C, Carlson SE, Clandinin T, Hornstra G, Neuringer M, et al. Long chain polyunsaturated fatty acids (LC-PUFA) and perinatal development. Acta Paediatr 2001;90(4):460-4.

[13] Araújo JR, Correia-Branco A, Ramalho C, Keating E, Martel F. Gestational diabetes mellitus decreases placental uptake of long-chain polyunsaturated fatty acids: involvement of long-chain acyl-CoA synthetase. J Nutr Biochem 2013;24(10):1741-50.

[14] Pagán A, Prieto-Sánchez MT, Blanco-Carnero JE, Gil-Sánchez A, Parrilla JJ, Demmelmair $\mathrm{H}$, et al. Materno-fetal transfer of docosahexaenoic acid is impaired by gestational diabetes mellitus. Am J Physiol Endocrinol Metab 2013:305(7):E826-33.

[15] Faul F, Erdfelder E, Lang A-G, Buchner A. G*Power 3: a flexible statistical power analysis program for the social, behavioral, and biomedical sciences. Behav Res Methods 2007;39:175-91.

[16] Shohet SB. The apparent transfer of fatty acid from phosphatidylcholine to phosphatidylethanolamine in human erythrocytes. J Lipid Res 1971;12(2): 139-42.

[17] Lubin B, Kuypers FA, Chiu D. Red cell membrane lipid dynamics. Alan R Liss Inc 1989:507-24.

[18] Kleinfeld AM, Storms S, Watts M. Transport of long-chain native fatty acids across human erythrocyte ghost membranes. Biochemistry 1998;37(22): 8011-9.

[19] Luxwolda MF, Kuipers RS, Sango WS, Kwesigabo G, Dijck-Brouwer DA Muskiet FA. A maternal erythrocyte DHA content of approximately $6 \mathrm{~g} \%$ is the DHA status at which intrauterine DHA biomagnifications turns into bioattenuation and postnatal infant DHA equilibrium is reached. Eur J Nutr 2012;51(6):665-75.

[20] Escolano-Margarit MV, Campoy C, Ramírez-Tortosa MC, Demmelmair H Miranda MT, Gil A, et al. Effects of fish oil supplementation on the fatty acid profile in erythrocyte membrane and plasma phospholipids of pregnant women and their offspring: a randomised controlled trial. $\mathrm{Br} \mathrm{J}$ Nutr 2013;109(9):1647-56.

[21] Miles EA, Noakes PS, Kremmyda LS, Vlachava M, Diaper ND, Rosenlund G et al. The salmon in pregnancy study: study design, subject characteristics, maternal fish and marine $n-3$ fatty acid intake, and marine n-3fatty acid status in maternal and umbilical cord blood. Am J Clin Nutr 2011;94(6 Suppl.) 1986S-1992S

[22] Simopoulos AP, Leaf A, Salem Jr N. Workshop on the essentiality of and recommended dietary intakes for omega-6 and omega-3 fatty acids. Asia Pac J CLini Nutr 1999;8(4):300-1.

[23] Min Y, Djahanbakhch O, Hutchinson J, Bhullar AS, Raveendran M, Hallot A, et al. Effect of docosahexaenoic acid-enriched fish oil supplementation in pregnant women with type 2 diabetes on membrane fatty acids and fetal body composition-double-blinded randomized placebo-controlled trial. Diabet Med 2014;31(11):1331-40.

[24] Salge AK, Rocha KM, Xavier RM, Ramalho WS, Rocha ÉL, Guimarães JV, et al. Macroscopic placental changes associated with fetal and maternal events in diabetes mellitus. Clin (Sao Paulo) 2012;67(10):1203-8.

[25] Arterburn LM, Hall EB, Oken H. Distribution, interconversion, and dose response of n-3 fatty acids in humans. Am J Clin Nutr 2006;83(6 Suppl.) 1467S-1476S.

[26] Olsen SF, Sørensen JD, Secher NJ, Hedegaard M, Henriksen TB, Hansen HS, et al. Randomised controlled trial of effect of fish-oil supplementation on pregnancy duration. Lancet 1992;339(8800):1003-7.

[27] Olsen SF, Secher NJ. Low consumption of seafood in early pregnancy as a risk factor for preterm delivery: prospective cohort study. BMJ 2002;324(7335): 447.

[28] Klebanoff MA, Harper M, Lai Y, Thorp Jr J, Sorokin Y, Varner MW, et al., Eunice Kennedy Shriver National Institute of Child Health and Human Development (NICHD) Maternal-Fetal Medicine Units Network (MFMU). Fish consumption, erythrocyte fatty acids, and preterm birth. Obstet Gynecol 2011;117(5): $1071-7$.

[29] Carlson SE, Colombo J, Gajewski BJ, Gustafson KM, Mundy D, Yeast J, et al. DHA supplementation and pregnancy outcomes. Am J Clin Nutr 2013;97(4): 808-15.

[30] Groh-Wargo S, Jacobs J, Auestad N, O'Connor DL, Moore JJ, Lerner E. Body composition in preterm infants who are fed long-chain polyunsaturated fatty acids: a prospective, randomized, controlled trial. Pediatr Res 2005;57(5 Pt 1): $712-8$.

[31] Lucia Bergmann R, Bergmann KE, Haschke-Becher E, Richter R, Dudenhausen JW, Barclay D, et al. Does maternal docosahexaenoic acid supplementation during pregnancy and lactation lower BMI in late infancy? J Perinat Med 2007;35(4):295-300.

[32] Donahue SM, Rifas-Shiman SL, Gold DR, Jouni ZE, Gillman MW, Oken E. Prenatal fatty acid status and child adiposity at age $3 \mathrm{y}$ : results from a US pregnancy cohort. Am J Clin Nutr 2011;93(4):780-8.

[33] Pedersen L, Lauritzen L, Brasholt M, Buhl T, Bisgaard H. Polyunsaturated fatty acid content of mother's milk is associated with childhood body composition. Pediatr Res 2012;72(6):631-6. 